\title{
Fertility in an Intergeneric Somatic Hybrid Plant of Rutaceae
}

\author{
S. Kobayashi, I. Oiyama, and K. Yoshinaga \\ Akitsu Branch, Fruit Tree Research Station, Akitsu, Hiroshima 729-24, \\ Japan
}

\section{T. Ohgawara and S. Ishii}

Research and Development Division, Kikkoman Corporation, Noda City, Chiba 278, Japan

Additional index words. protoplasm fusion, citrus breeding

There are many species in the family $R u$ taceae that are difficult to sexually hybridize because of problems related to their sterility and/or polyembryony. Protoplasm fusion provides an alternative way for producing hybrids between such species. In 1985, we developed a protoplasm fusion procedure in citrus and produced intergeneric somatic hybrid plants between 'Trovita' sweet orange [Citrus sinensis (L.) Osb.] and trifoliate orange (Poncirus trifoliata Raf.) (Ohgawara et al., 1985). Many other somatic hybrids of citrus have been produced since then by a similar procedure (Grosser et al., 1988; Kobayashi et al., 1988; Ohgawara et al., 1989). These somatic hybrids were morphologically normal, vigorous, and had the expected amphidiploid chromosome number of 36 . It is important to determine whether these somatic hybrids are fertile. One of our somatic hybrids between 'Trovita' sweet orange and trifoliate orange has reached the flowering

Received for publication 24 May 1990. Contribution no. Fruit Tree Res. Sta. E-128. The cost of publishing this paper was defrayed in part by the payment of page charges. Under postal regulations, this paper therefore must be hereby marked advertisement solely to indicate this fact. stage. We report herein the flower and fruit characteristics and fertility of this somatic hybrid.

In 1985, the six clones of the somatic hybrid were top-grafted onto 7-year-old nucellar seedlings of satsuma mandarin (C. unshiu). One of the clones developed 50 flowers and set fruit in 1989. Although half of the flowers had an abortive pistil, one of the normal flowers set a fruit. The flower morphology of the somatic hybrid was intermediate to that of the parents. Petals were spoon-like in shape, as for trifoliate orange, and the stigma resembled that of sweet orange. The ovary of the somatic hybrid was spherical, as for sweet orange, and highly pubescent, as for trifoliate orange (Fig. 1). Pollen germinability of the somatic hybrid was determined by a germination test on an agar medium (2\% agar and $20 \%$ sucrose) at $25 \mathrm{C}$ for $20 \mathrm{~h}$. Ten flowers were used for the germination test, and $\approx 500$ pollen grains in each flower were examined from two plates. Pollen from the somatic hybrid had $\approx 50 \%$ terminability. The fruit of the somatic hybrid weighed $100 \mathrm{~g}$, had a diameter of $6.8 \mathrm{~cm}$, and an irregular oblate shape. The rind was rough and extremely thick (Fig. 2). The juice was scant and acidic and had an unpleasant flavor. The somatic hybrid had one well-developed pol-

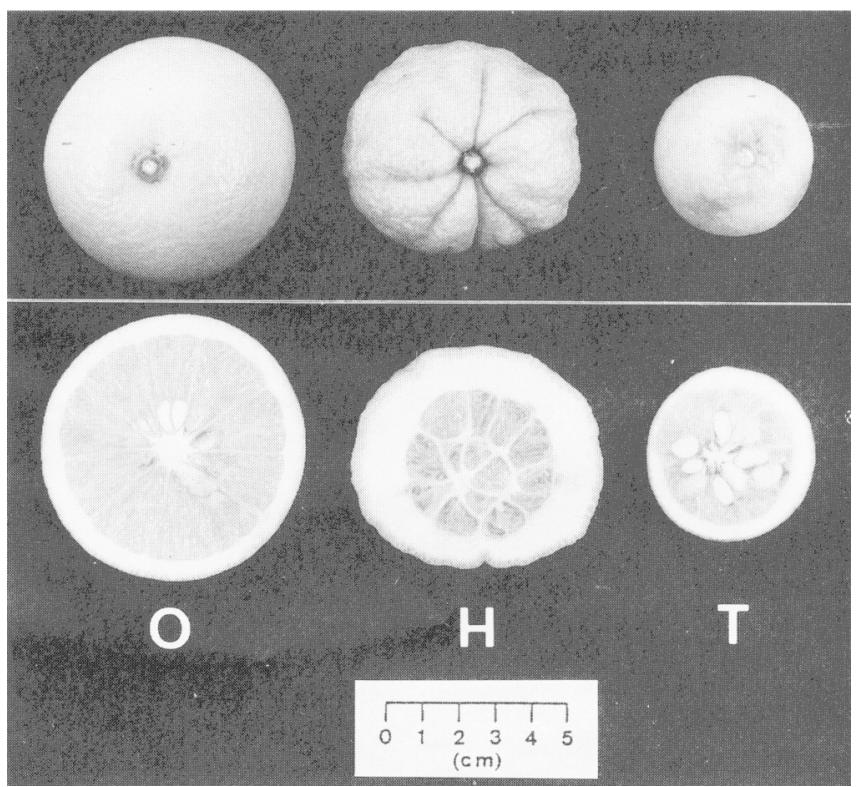

Fig. 2. Whole and cut fruits of 'Trovita' sweet orange (O), trifoliate orange (T), and somatic hybrid (H).

Fig. 3. Seedling of the somatic hybrid. 